\section{THE LARYNGOSCOPE AND ITS CLINICAL APPLICATION.}

By Thomas James Walker, M.D.(Lond.), etc., Surgeon to the Peterborough Infirmary and Dispensary.

\section{III.-Appearance of the Normat: Larynx, etc., as SEEN IN THE LARYNGOSCOPE.}

Having described at length the instruments which we require in order to obtain a view of the larynx, and to treat its morbid conditions, I think it well, before giving directions for their practical application, to call to the remembrance of our associates, the different parts of the larynx and pharynx, and to indicate the appearance which these present when viewed in their normal condition by aid of the laryngoscope. In doing this, I do not think it necessary to give a minute account of each fold or fossa observed, nor to aiscuss the physiological bear. ing of the various structures; but simply to give such a description as may enable the observer at once to recognise what he sees and to distinguish what is healthy from what is morbid.

The parts of which the larynx-speculum affords us a view are, the back of the tongue, the whole interior of the pharynx, the larynx with all its constituent parts, a part of the interior of the trachea, and a part of the nasal cavities.

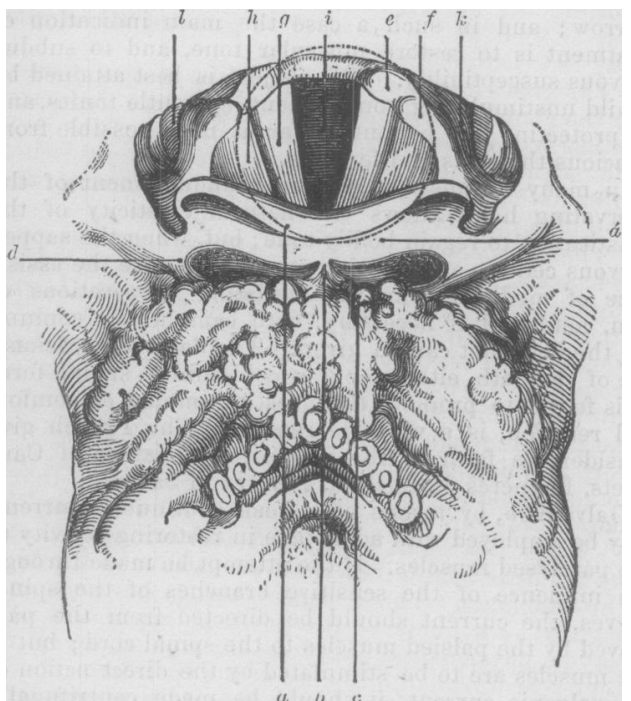

Fig. 6.-The base of the tongue and the laryux, etc. The dotted circle inciudes as much of the parts as is seen at one time in a moderately sized mirror. 'The engraving, with the excention of this ring, is taken from Türck.

On first introducing the instrument into the fauces, we meet with the image of the back of the tongue; and so little are we accustomed, when unaided by the laryngoscope, to examine this part of the body, that the $V$. shaped group of large circumvallate papillæ, and the generally irregular, almost warty, appearance of the surface of the base of the tongue, inight be regarded as abnormal by the observer using the specuium for the first time. Even when the rest of the tongue is much furred, the elevations and irregularities at this part of the organ are free from fur, and they then show more distinctly against the surrounding surface. The mirror being advanced a little further towards the back of the pharynx, the epiglottis $(a)$ is brought into view; when the tongue is drawn forward at the same time that the epiglottis remains in its usual position, we see that, stretching across the angle formed between the front of the epiglottis and the surface of the tongue, is the glosso-epiglottic ligament $(b)$, which, passing from the centre of the base of the tongue back to the middle line of the front of the epiglottis, leaves on each side of it a deep fossa (c), named the vallecula; this groove is separated laterally from that in which the tonsil lies, by a band, more or less marked, passing from the base of the tongue, backwards and outwards, towards the hyoid bone. When the tongue lies quietly at the base of the mouth. its surface at the base and the anterior surface of the epiglottis are in contact, so that the valleculæ, etc., are not seen.

Immediately behind these parts, and always constituting a prominent object in the mirror, is the epiglottis (ai). This portion of the larynx differs much in appearance in different subjects; it is at once recognised standing up from the root of the tongue, of a more or less decided yellowish tinge; the yellow colour being more marked at the border, which presents a curved outline, the convexity of the curve being directed forward at the centre, while at the sides it is in the opposite direction. It is in the greater or less degree of these curves, in the more or less pointed character of the centre of its border, in the extent to which it stands up from the tongue, and in the intensity of the yellow tinge, that the epiglottis differs in different individuals. Thus, without being abnormal, the free part of the epiglottis may present the appearance of a thin, yellow, sinuously curved lamina, stretching from side to side of the fauces; or of a pink, thick, almost conical process, standing up at the centre of the back of the tongue. These differences in form uppear to be independent of the character of the voice.

The position of the tongue and of the larynx, as well as the action of the muscular fibres connected with the epiglottis, regulates the amount of the surface, anterior or posterior, of the epiglottis which we see. It is most difficnlt to get a view of the posterior surface; and almost always, in our first examinations of the larynx, it is the anterior surfuce $(\dot{a})$, with the frænulum or glossoepiglottic ligament, which we catch sight of in the mirror; but by asking the patient to utter a high falsetto note, and in some cases without this, we may get a view of the posterior surface. This surface of the epiglottis is smooth; and may be described in general terms as convex from above down, concave from side to side; although Dr. Czermak has called attention to the fact alluded to in the minute descriptions of some of the old anatomists, that the curve from above downwards varies slightly in its course from the base to the summit of the epiglottis. Dr. Czernık has also pointed out the existence of a small prominence in tho middle line, at the base of this surface; and whether this nodule have the physiological importance which he ascribes to it or not, $i t$ is as well that those inspecting the interior of a larynx should be aware that this nodule, when seen more or less developed, indicates nothing patbological.

The epiglottis $(a)$ forms the anterior boundary of that part of the laryngeal wall which stands up free in the pharynx; the arytenoid cartilages $(e)$, with the arytenoepiglottidean folds containing the cartilages of Wrisberg $(f)$, constituting the remainder of this portion. This part of the larynx lies within the expanded alr of the thyroid cartilage and the greater cornua of the hyoid bone, which are concealed in the pharyngeal wall; and it is supported on the cricoid cartilage, which lies imbedded in the surrounding tissues, so that only its inner surface can be seen without dissection.

'The mucous membrane is reflected off the edge of the epiglottis towards the wall of the pharynx, expanding over the inner surface of the hyoid bone, thyroid cartilage, and pharyngeal muscles; while another fold, pass- 
ing at a lower level backwards towards the arytenoid car. tilages, and containing between its layers the fibres of the aryteno-epiglottideus muscle and the cartilages of Wrisberg, constitutes the aryteno-epiglottidean ligament.

Now, of these parts, that which next to the epiglottis usually constitutes the most prominent object in the laryngeal image, is the summit of the arytenoid cartilage surmounted by the cartilages of Santorini $(e)$.

Even where the epiglottis is but imperfectly raised, these prominences may be seen on either side of the middle line, behind its upper edge; and they will pro. bably be illuminated, even though an unaccustomed operator may not hold the mirror so as to throw into the interior of the larynx sufficient light for the display of the vocal cords.

It is hardly necessary to remind my readers that the arytenoid cartilages have the form of irregular threesided pyramids, and are placed with their bases on the cricoid cartilages, while on their apices are situated the little cartilages of Santorini. As seen covered by the mucous membrane, these apices and the supplementary cartilages present the appearance of two rounded nodules, situated at the back part of the upper boundary, and constituting the apex of the somewhat triangular upper opening of the larynx. These nodules are in contact or slightly separated, according to the active or passive state of the vocal cords ; the mucous membrane covering the prominences is smooth and pink; the cartilage, however, in some cases, shining through, gives it a yellow tinge, and the peculiar form of the conical apex curving backwards and outwards, clearly shows itself. The position of the mirror being shifted a little, or the epiglottis being carried more forward, the rounded, smooth, pink, aryteno-epiglottidean folds, are seen stretching outwards and forwards (upwards in the image) to the margin of the epiglottis, and forming the two sides of the triangular opening of the larynx. The cartilages of Wrisberg $(f)$, lying in the edge of these folds, immediately in front of the arytenoid cartilages, constitute, in some individuals, prominences no less distinct than those formed by the latter, while in others they are scarcely observable.

Although the parts situated external to this upper boundary are to be noticed and require description, it is to those situated deep within the space it includes, to the true and false vocal cords and the laryngeal pouches that our attention is usually directed. Of these objects, the most prominent and the most important are the true vocal cords $(g)$. They are seen as two tense white bands, about a line in width, stretching from before backwards, seldom seen at first in their whole length; the anterior angle, formed where they meet at their insertion into the lower part of the angle of the thyroid cartilage, being demonstrable only when the conditions are most favour. able for the examination of the larynx.

If the patient be breathing quietly when the rocal cords come into view, they are seen to diverge, as they pass backwards to their insertion into the hase of the arytenoid cartilages, so as to be separated posteriorly by an interval of half an inch or so. If the larynx be half closed, the vocal cord is seen to terminate in the prominent angle at the base of the arytenoid cartilage called the vocal process; and these vocal processes, in this state of the larynx, converging backwards, give to the rima glottidis the form of an elongated irregular lozenge. Our attention is, however, usually arrested by the vocal cords, when they are made to approach one another by the patient's uttering a vowel sound. Being thus made tense, they are thrown well out into the middle line, where there is, when the mirror is rightly held, the most brilliant light. Under these circumstances, they appear very distinct, of a bright white colour, and separated from one another by a narrow chink. If our patient is able to utter a prolonged high falsetto note, he can, by so doing, display his vocal cords very clearly in their whole length, parallel, and separated only by a scarcely perceptible fissure at their posterior part.

The mucous membrane covering the vocal cords is reflected from their under surface on to the cricoid cartilage and trachea; and, of course, neither the under surface of the cords, nor the part of the cricoid immediately below them, can be seen in the mirror held in the pharynx as I have described; from the upper surface of the cords, the mucous membrane is reflected on to the laryngeal wall, and about a line above them it forms a fold on either side called the false vocal cords $(h)$; these projecting from the wall of the larynx but a short distance, still catch the light so as to be prominent objects in the laryngoscope; the mucous membrane is of the same pink hue at these folds as over the rest of the larynx, the small proportion of fibrous tissue contained between their layers not showing through; the sulcus existing between the true and false vocal cords, called the laryngeal sinus or ventricle, remains dark and in shadow in the laryngoscopic image, and is thus recognised between the bright fold of the false vocal cord above, and the glistening, tense, almost white band, the true vocal cord, below.

In most cases where we get a good view of the larynx, we may, by a little dexterou 3 management of the mirror, shoot a ray of ligbt down through the rima glottidis $(i)$ into the trachea, so as to render the mucous membrane lining it visible, with the cricoid cartilage and the tracheal rings showing white and prominent through the translucent membrane. Very rarely the whole length of the trachea is thus illuminated, and the openings of the bronchial tubes into which it divides may be seen. By shifting the mirror, different parts of the tracheal wall may be seen, and ulcers, or other pathological affections, may be discovered.

The great freedom and rapidity of motion possessed by the chordæ vocales, cannot fail to strike the observer on his first obtaining a view of the interior of the larynx; the mobility is best seen when the person subjected to examination forces a laugh or cough, or utters a succession of vowel-sounds.

The false vocal cords do not possess any amount of independent action, but they approximate and diverge slightly, according as the general shape of the larynx is altered. Thus, in uttering a high falsetto note, the whole larynx is compressed from side to side, elongated from before backwards, and, of course, the false cords are approximated; so also, in the act of retching, the base of the tongue being depressed, the epiglottis stands very prominently up, and the sides of the larynx appear to approximate; in swallowing, it is probable that the false cords are also approximated, while, according to Czermak, the small fissure left between them is closed by the little nodule described as existing at the back of the epiglottis. These papers being, however, meant merely as a guide to the practical application of the larynx, physiological questions are avoided, except when they bear directly on the use of the speculum.

I have already stated that the walls of the larynx, within which are situated the parts just described, stand up free in the pharynx. On either side of these, therefore, is a sulcus bounded internally by the outer surface of the arytenoid cartilages and ary teno-epiglottidean ligaments $(k)$, externally by the wall of the pharynx $(l)$; in the outer wall of this groove, shining through the mu. cous membrane, and forming a more or less decided whitish prominence, may be seen the greater cornu of the hyoid bone; this fossa is not unfrequently the site in which foreign bodies, as small pieces of bone, etc., lodge and cause much annoyance.

At the back of the arytenoid cartilages, the mucous membrane is continuous with that of the pharynx; and here is situated the opening of the csophagus; but of this opening nothing is seen, it being, in the normal state, so firmly closed that the mucous membrane 
appears to be reflected from the base of the arytenoid cartilage on to the posterior wall of the pharynx.

There still remains to be described the appearance which the part of the pharynx situated above the level of the soft palate presents when, the face of the mirror being turned upwards, the posterior nares, orifices of the Eustachian tubes, etc., are seen reflected in it.

The practice of rhinoscopy, as the examination of these parts has been termed, is attended with many more difficulties than the examination of the larynx; and, in an ordinary case, it is hardly possible to get so full a display of the parts as that given in the accom. panying engraving, which is an accurate representation of the appearance which they presented in a case where, the soft palate being completely divided, special facilities for their observation existed. I have, however, drawn the palate as though undivided and raised by a spatula; since, the bright eind of the palate-spatula $(f)$ being one of the first of the objects reflected in the mirror which catches the eye of the cibserver, a clear conception of its relation to the surrounding parts will assist him in adjusting the mirror so as to bring these into view.

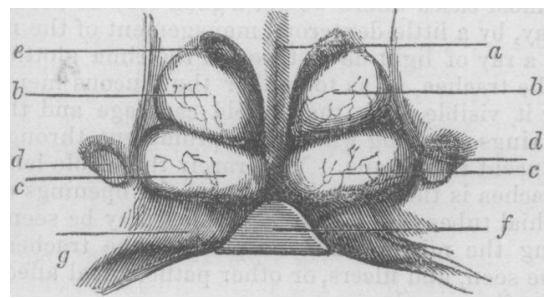

Fig. 7.-View of the posterior nares, tlie eustachian tubes, etc., as seen during lite in the laryngoscope.

It is quite the upper part of the pharynx, with the expanded portion of the septum $(a)$ forned by the base of the vomer, the two middle spongy bones $(b b)$, and the nasal cavity between them, which, when the mirror is held in the middle of the pharynx, are first and most readily seen. It is more difficult to get a good view of the lower spongy bones $(c c)$, and of the lower portion of the romer, which parts are in shade from the promi nence of the soft palate. The openings of the Eus. tachian tubes $(d d)$ can be seen by sloping the mirror to one or other side.

The idea which we should form of the appearance of these parts from an examination in the recent state after death, or still more the idea formed from a knowledge of the skeleton in this region, is found to be very inadequate when we examine the nares during life.

The posterior edge of the septum narium $(a)$ is seen now as a brightly illuminated pink column gradually tapering from the roof of the nostril to the floor, the lower portion receding between the prominent expan. sions of mucous membrane over the lower turbinated bones. At its upper and widest part, the septum is slightly grooved in the middle line; and here the mu cous membrane appears whitish, from the vomer showing through. On either side of the septum are seen the rounded prominences of mucous membrane $(b b)$ which project from the middle turbinated bones; they have a smooth shining surface, with a bluish tinge; and minute vessels are seen ramifying over them. The two are not absolutely srmmetrical in size or form; they almost completely fill the upper part of the nares, and project back to a level with the border of the septum. Situated below these, and so close upon them that no view of the interior of the middle meatus is obtained, are the corre sponding expansions over the lower spongy bones $(c c)$. they are more flattened from above downwards, elongated laterally; they present a similar smooth rounded surface, with a slightly blne tinge, to that already 208 described on the middle bones; they project further back into the pharynx than these. Situated more deeply in the superior meatus may be sometimes seen the small fold of mucous membrane corresponding to the superior ethmoidal spongy bone (e). These parts occupy almost completely the space of the posterior nares: but between them and the septum and floor of the nose are seen the dark spaces into which they divide the nasal cavity. The direction in which the light is thrown and the position of the mirror prevent our having a direct view into these, and cause the meatuses to appear in the engraving rather smaller than they actually are.

Situated in the lateral wall of the pharynx, immedi. ately below and to the outer side of the attached edge of the lower turbinated processes, is, on either side, the orifice of the Eustachian tube $(d d)$; these are irregular oval orifices, looking downwards and inwards, measuring, in their longest diameter, from two to three lines; the upper and posterior edge of the trumpet shaved opening of the Eustachian canal being bevelled off, we see the inner surface of the anterior lip, buried in the pharyngeal wall, apparently of a lighter colour than the surrounding mucous membrane, and having a yellow tinge communicated by the cartilage beneath it. In its course backwards and inwards to the ear, the tube causes a rounded prominence of the mucous membrane, as represented in the drawing. From the side of the pharynx at this point, the mucous membrane is reflected on to the soft nalate; and a prominent fold exists at the lower edge of the orifice of the Eustachian tube, beneath which lie the fibres of the levator palati muscle. Of the objects I have mentioned, not only those situated at the uppermost part of the pharynx, but also the orifices of the Eustachian tubes, may be easily illuminated in any case where we find a palate capable of tolerating the spatula necessary to raise it; the mirror having its face directed laterally, to throw the light on to the parts situated out of the middle line. The lower part of the vomer and lower turbinated bone are, however, thrown into shadow by the soft palate $(g)$ and the end of the spatula $(f)$ with which we raise the uvula and draw the velum forward.

Of course, by using a small mirror and turning it to one sille or the other, we may get a view of any part of the pharyngeal wall, and thus detect ulcers, morbid growths, and other abnormal conditions; but there is nothing more seen in the normal state of the parts which requires description.

[To be continued.]

The Cervix Uteri in Pregnancy. Dr. Natthews Duncan exhibited, at the Edinburgh Medico-Chirurgical Society, a dissection of the cervix uteri of a woman who died in the eighth month of pregnancy. She came into the Royal Infirmary labouring under typhus fever, and was under the care of Dr. Warburton Begbie. The length of the cervix was about an incb. Its external extremity, marked by an irregular row of Nabothean follicles, could be easily seen; and its internal extremity, continuous with the rapidly expanding smooth internal surface of the body of the uterus, was also dis tinct. The whole cervix was hypertrophied and softened; and this remark applied also to the arbor vitæ, of which the anterior and posterior columns were strongly projected. Dr. H. S. Wilson had, at his request, examined the internal surface of the body of the uterus microscopically, after detaching the chorion from it; and he had found no denudation of the muscular fibres, but the surface formed of a layer, detachable in an early stage of putridity, composed of decidual structures, especially of fusiform nucleated cells, which seemed to be less fusiform in shape and rounder the nearer they were to the chorion. (Edin. Med. Journal.) 